IRA-International Journal of Technology \& Engineering

ISSN 2455-4480; Vol.04, Issue 03 (2016)

Pg. no. 126-134

Institute of Research Advances

http://research-advances.org/index.php/IRAJTE

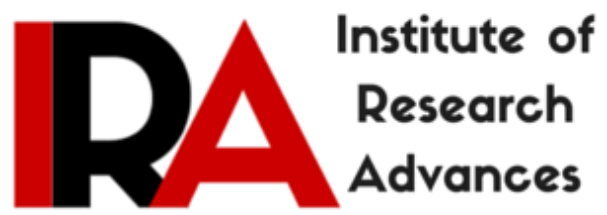

\title{
A Mechatronic System to Prevent Death due to Suffocation in a Locked Car
}

\author{
Mallikappa DN Dodderi ${ }^{*}$, Rao Sukesh Raghavendra ${ }^{2}$, Narayana Hegde ${ }^{3}$, \\ Navaneeth Rao I ${ }^{4}$, Mohammed Asif ${ }^{5}$ \\ 1* Professor, Mechanical Engineering Department, NMAM Institute of \\ Technology, Nitte-574110, India. \\ ${ }^{2}$ Design Trainee, INTECH DMLS, Mulki, Mangalore 574154, India. \\ ${ }^{3}$ Marketing Engineer, Maruthi Enterprics, Anekere, Karkala-574104, India. \\ ${ }^{4}$ Mechanical Engineer, Iddya, Surathkal, Mangalore-575014, India. \\ ${ }^{5}$ Mechanical Engineer, Karangalpady, Mangalore-575003, India.
}

Type of Reviewed: Peer Reviewed.

DOI: http://dx.doi.org/10.21013/jte.v4.n3.p1

\section{How to cite this paper:}

Dodderi, M., Raghavendra, R., Hegde, N., Rao I, N., \& Asif, M. (2016). A Mechatronic System to Prevent Death due to Suffocation in a Locked Car. IRA-International Journal of Technology \& Engineering (ISSN 2455-4480), 4(3), 126-134.

doi:http://dx.doi.org/10.21013/jte.v4.n3.p1

(C) Institute of Research Advances

\section{(cc) EY-NO}

This work is licensed under a Creative Commons Attribution-Non Commercial 4.0 International License subject to proper citation to the publication source of the work.

Disclaimer: The scholarly papers as reviewed and published by the Institute of Research Advances (IRA) are the views and opinions of their respective authors and are not the views or opinions of the IRA. The IRA disclaims of any harm or loss caused due to the published content to any party. 


\begin{abstract}
Automation of anti-suffocation system has become a very essential part of safety in automobile. The death of toddlers, disabled people and animals due to suffocation in locked cars has been a significant problem. Hence, there is a requirement for a system which autonomously operates with minimal power consumption and cost to overcome this sort of harm to human life.

In this work an attempt has been made to develop a system that works invariably, irrespective of negligence of person handling the car. This system is a prototype vehicle model of how sensors and actuators can be appropriately used as a setup to overcome this problem.

The setup consists of a prototype vehicle, with engine cut off and all the doors closed, a temperature sensor, a motion sensor, a microcontroller and actuator and the power supply is provided by a battery.

Results indicate that, with the help of sensors and actuators window glass is lowered and circulation of fresh air takes place, temperature inside the car is lowered; this system prevents suffocation by intelligent sensing which works efficiently, this is an economical system without any compromise on its functioning.
\end{abstract}

Keywords: Mechatronic system, Anti suffocation, Sensors, Actuators, Prototype.

\title{
1. INTRODUCTION
}

Today we come across cases like death of a child due to suffocation in a locked car. In a recent case, where two sisters within 5 years of age playing got the car key and entered the car. Car got centrally locked when they closed the door. Unfortunately the two sisters didn't know how to open the door and got locked in with windows closed. Parents were unaware and were searching inside and outside the house. Several hours later they noticed the missing car key and ended up finding their children dead inside. Later they came to know that cause for the death was suffocation (The Hindu, 2015).

The above is one of the alarming cases which are less known but a rising cause of deaths in India. In U.S this is one of the major case were children are left in cars parked in hot sun unknowingly by parents or guardians. On an average, 38 children die in hot cars each year from heat-related deaths after being trapped inside motor vehicles and 719 children have lost their lives since 1998 (Kids and car, 2016). Even the best of parents or caregivers can unknowingly leave a sleeping baby in a car; and the end result can be injury or even death. These problems are not limited to children but can also be equally dangerous to pets, disabled and physically challenged.

Vehicles when parked in hot environment without overhead garages, with engine off, doors and windows closed and outside temperature above $33^{\circ} \mathrm{C}$, the inside temperature may rise above the comfort limit in a short time. This may lead discomfort to the driver or passengers if present inside and cause hyperthermia for a child or disabled.

The major objective of this work is to reduce heat from the car cabin. So to avoid this, easy solution is to keep the window open. Heat always flows from higher concentration region to lower concentration region. In a closed parked car, heat is accumulated inside the cabin hence it becomes a region of higher concentration. Lowering the window will allow the accumulated heat to move out and hence reduce the cabin temperature.

Lowering the window may pose threat to security of the valuables and privacy. Hence this mechatronic system lowers the window by a predefined amount when the undesirable conditions are reached. This causes the temperature to drop inside the car. The window is raised automatically when the conditions inside the car reaches normal state.

The setup consists of a prototype vehicle, with engine cut off and all the doors closed. The temperature sensor senses the temperature of the interior and when the temperature rises above the 
comfortable temperature range, presence of the child is detected by the motion sensor which senses the movement of child and pressure sensing component placed on seats which senses the weight and a signal is sent to microcontroller. This in turn actuates the actuator placed on the windows there by lowering the window glass by predefined amount. The actuator mainly includes servomotor and linkages. Required power supply is provided by battery. Hence the system being developed uses mechatronic components in the most efficient and economical way.

\section{LITERATURE REVIEW}

From the published information's, following are the experimental research that has been carried out in this area.

\subsubsection{Heat Stroke Prevention System}

"System and method for preventing entrapment and heat suffocation in vehicles"

(Dulin, 2002).Safety system for passenger vehicles to prevent entrapment of child, disabled, aged or infirm person or pets being left in sun so that they will not suffocate from heat. The invention is characterized by use of one or more systems to sense the occupancy state, temperature inside vehicle and provide one or more outputs which can be selectively employed to provide warning to permit rescue and or activate electro mechanical systems to relieve heat. System includes microcontroller, sensors and electromechanical system. Sensors include automotive occupancy sensor (AOS), ultrasound sensor, I.R. sensor, imaging sensor, microphone sensor, seat sensor, capacitance sensor, motion sensor, floor sensor, temperature sensor.

Electro mechanical system includes rolling down windows, unlatching seat belts, unlocking doors, starting car, fan or air conditioning system.Interior warning includes illuminated warning, voice announcement or warning sound.Exterior warnings include vehicle lights, horns, alarms, out bound RF message.

\subsubsection{Automatic Window and Sunroof Adjusting}

"Vehicle for automatically adjusting window and sunroof positions after it being left unattended by its operator" (Liu, 2001).When an automobile is parked outside without overhead garages and with its windows closed or open it may be subjected, respectively, to freezing or overheating its interior depending upon its exterior temperature. Such extreme temperature will reduce the life span of electronic and mechanical components in or near the interior, cause discomfort to the passenger or driver and danger of life to kids, pets or disabled. System includes temperature sensing circuitry to sense interior temperature, microcontroller to sense the input signal and give the actuation signal to lower or close the power windows and sunroof.

\subsubsection{Alerting, Monitoring and Controlling System}

"System for Alerting, Monitoring and Controlling Heat Stroke inside Vehicles" (Garethiya, 2015).Has proposed a simple and effective solution to alert vehicle owners about the possibility of heatstroke inside it if any person is present and thus apparently avoiding death due to suffocation. And also making system beneficial not only to the owner but also to the law enforcing agencies, using sensor and electronic units. System includes Temperature sensing, Pressure detection, GPS and real time modules

\subsubsection{Image Motion Detection System}

"Car Suffocating Prevention Using Image Motion Detection" (Muhamad and Rasidi, 2013).Video based system to automatically check whether there are any human left in car when the engine has been turned off to avoid suffocation. Working: System starts when car engine is turned off and doors are locked. System then checks if there is any movement inside the car. If any movement is detected alarm is triggered until owner comes and turns it off. If no movement is detected for about 30 minutes, it will automatically get deactivated. Hardware: Raspberry Pi, BTC PC 380 webcam. Two cameras have been setup above right front and left back of window glass with 30 degree downwards so that they will only focus on car seats. 
Testing condition variables are; Controlled variables, Different body sizes, Different body position, Different objects, Condition where human and object exist inside the car

\subsubsection{Thermal Protection for Vehicle}

"Vehicle having a thermal protection arrangement for toddlers and pets" (Liu, 2001).A method and apparatus is provided for automatically adjusting a vehicle's window and sunroof positions after the vehicle is parked and the vehicle operator left it unattended. Once activated, the power window and sunroof system will be disabled automatically when the vehicle operator returns to drive the vehicle away. The present invention also has a temperature sensing circuitry to be appropriately located somewhere in or near the interior of the vehicle. One aspect of this includes a control pane in the vehicle interior for the operator setting of temperature range, the window and sunroof ventilation positions. Another aspect of this includes means of communication to alert the vehicle operator and others in case of exceedingly high or low temperatures in the vehicle interior that might be lifethreatening to the toddlers, pets or other incapacitated living beings who are left unattended in the vehicle.

\subsubsection{Thermal Distribution within Car Cabin}

"Computational Analysis of Thermal Distribution within Passenger Car Cabin" (Quadri and Jose, 2013).The analysis of the car model was done by analyzing that the car is kept in longitude and latitude in New Delhi from 2 pm onwards on $10^{\text {th }}$ day of 4 month. When the Solar radiations fall on the window panes the areas around them experienced the highest temperatures and a porous slit positioned above the windows could act as a vent for hot air. From the simulation it was evident that the location of the vents plays a vital role in determining the cabin environment. When a vehicle is parked under the sun, accumulated heat affects many interiors, thus bringing about their degradation this study can be used effectively to prevent this.

From the above literature survey it has been shown that car parked in sunlight is dangerous not only to kids but every human being, and car itself. Hence there is need for a system which is economical and which works effectively under any conditions and saves precious lives. Death of kids due to heatstroke in car cabin is raising continuously even though people are made aware of this type of problem. Solutions though present are not so efficient and are not economical so that it can be used by mass number of people. So we are developing an economical and efficiently working mechatronic system.

\section{METHODOLOGY}

The system includes following components:

1. Temperature sensor.

2. Pressure Sensing Element.

3. Motion sensor.

4. Servomotor.

5. Atmega328P I.C.

3.1 Principle of working: System consists prototype of a vehicle, with engine cut off and all the doors closed. The temperature sensor senses the temperature of the interior and when the temperature rises above the comfortable temperature range, presence of the child is detected by the motion sensor which senses the movement of child and pressure sensing component placed on seats which senses the weight and a signal is sent to microcontroller. This in turn actuates the actuator placed on the windows there by lowering the window glass by predefined amount. The actuator mainly includes servomotor and linkages. Required power supply is provided by battery.

It also includes working of the system and experiment conducted, to see how temperature rises in a closed parked car. 


\subsection{DESIGN OF THE SYSTEM}
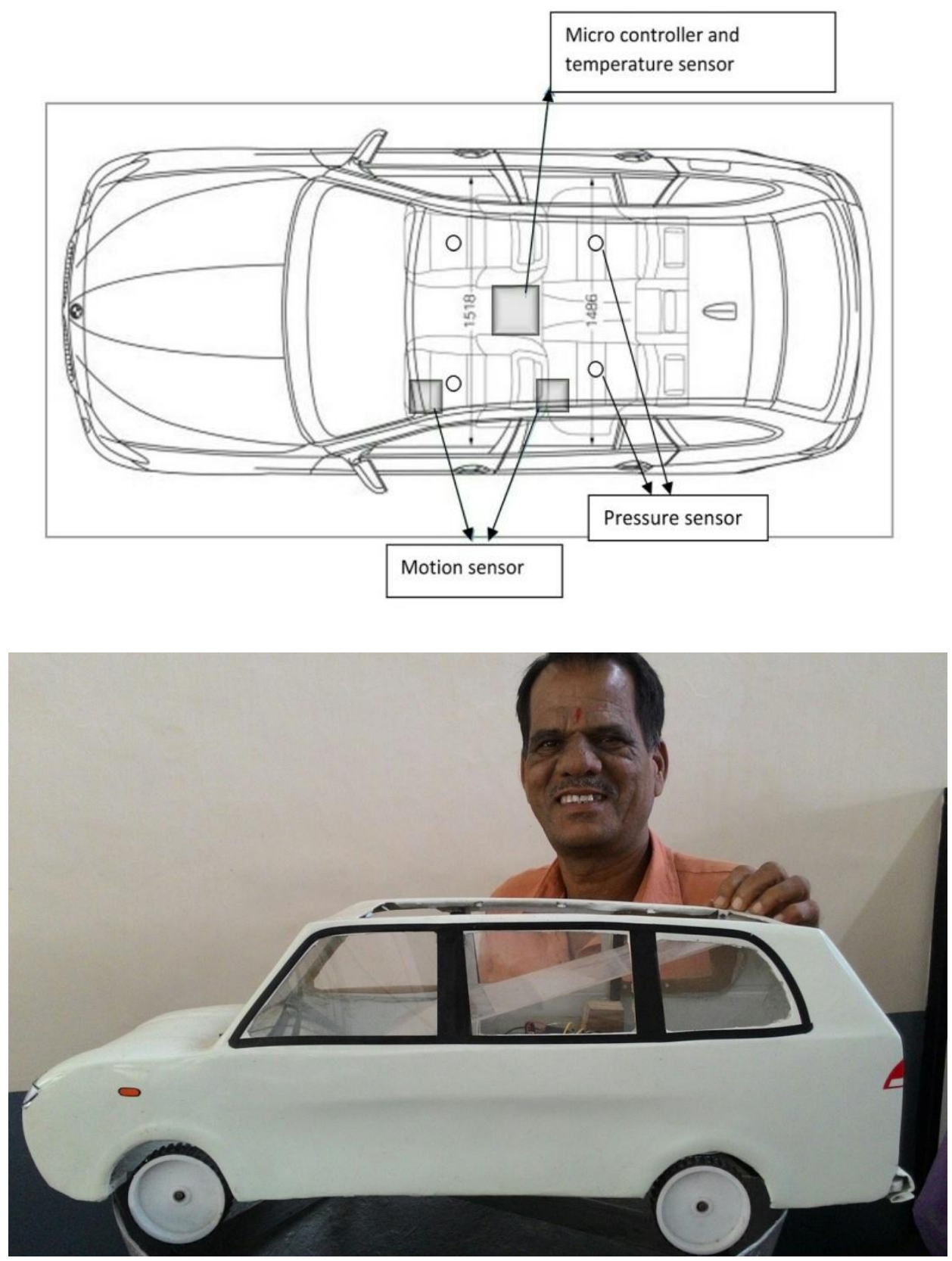

Fig 3.1 Design of the system

In the mechatronic system as shown in the fig 3.1 temperature sensor is placed in the centre of car cabin where it senses for temperature. The microcontroller of the system is placed in the same location. Pressure sensors are placed on seats to sense weight. The motion sensor is located above the window glass in front and rear end of the car.

\subsection{Sequence of operation of the system}

The following flow chart shows the sequence of operation of the system. 


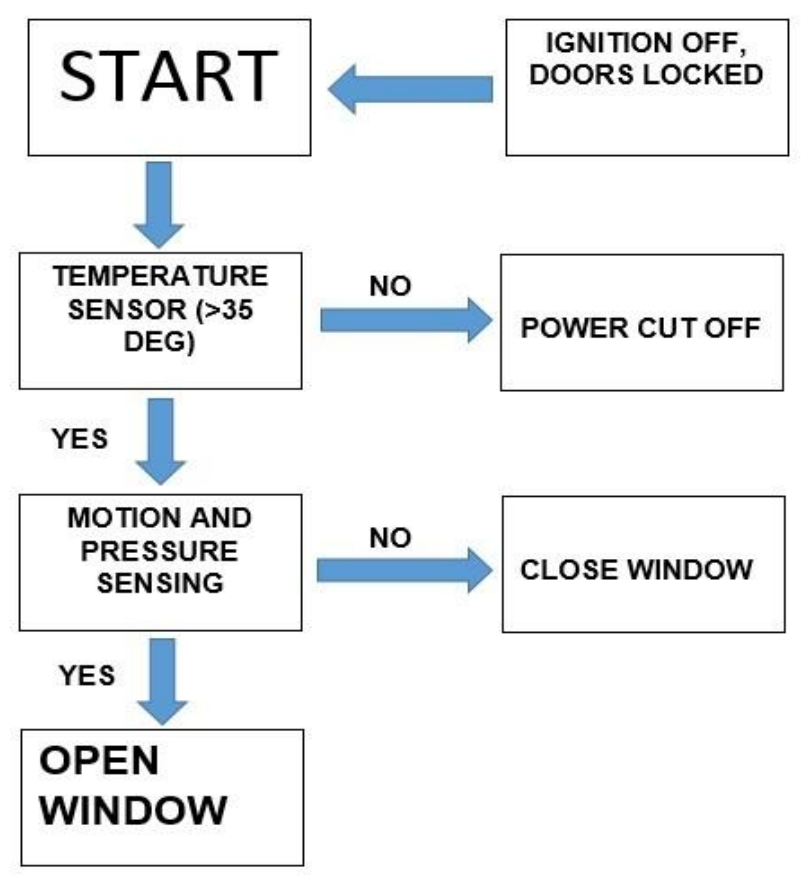

Fig 3.8 Working of the system

$\checkmark$ The system starts only when engine is turned off.

$\checkmark$ Doors and windows are closed or centrally locked.

$\checkmark$ As these conditions are achieved temperature sensors gets on and checks temperature in the car cabin.

$\checkmark$ If no temperature rise is seen then the windows will be in closed position assuming that the car is parked in shade.

$\checkmark$ If the inner temperature is found to be above human comfort limit then motion and pressure sensor gets activated.

$\checkmark$ Motion sensor checks for any motion inside the cabin and pressure sensing element senses for weight on the seat.

$\checkmark$ These two working simultaneously ensures that any living being is present and not a bag.

$\checkmark$ Microcontroller gives command to servomotor and it rotates by a required amount to lower the window and allows cool air to enter the cabin.

$\checkmark$ After some time when the temperature is lowered, temperature sensor senses and again actuates the servomotor to close the window.

$\checkmark$ Thus heat is liberated, life inside is secured and security is maintained.

$\checkmark$ Window movement mechanism is done by scotch yoke mechanism, which is having two sliding pairs and these convert rotary motion to linear or reciprocating motion.

3.3.1 Experimental Procedure: To determine the variation of temperature with time in a closed car and car with widows lowered.

- Car is placed in hot sun without any overhead carriages. The engine is turned off and windows are closed.

- The temperature sensor setup is placed at the centre of car cabin.

- At regular intervals of time, temperature readings are noted from the display unit.

- A graph of temperature vs. time is plotted.

- The above procedure is repeated with windows open and graph is plotted. 


\section{Results and discussion}

It gives in brief general idea of possible outcomes, experimental analysis result and advantages of the system.

A prototype of car has been developed and our system has been implemented in it.

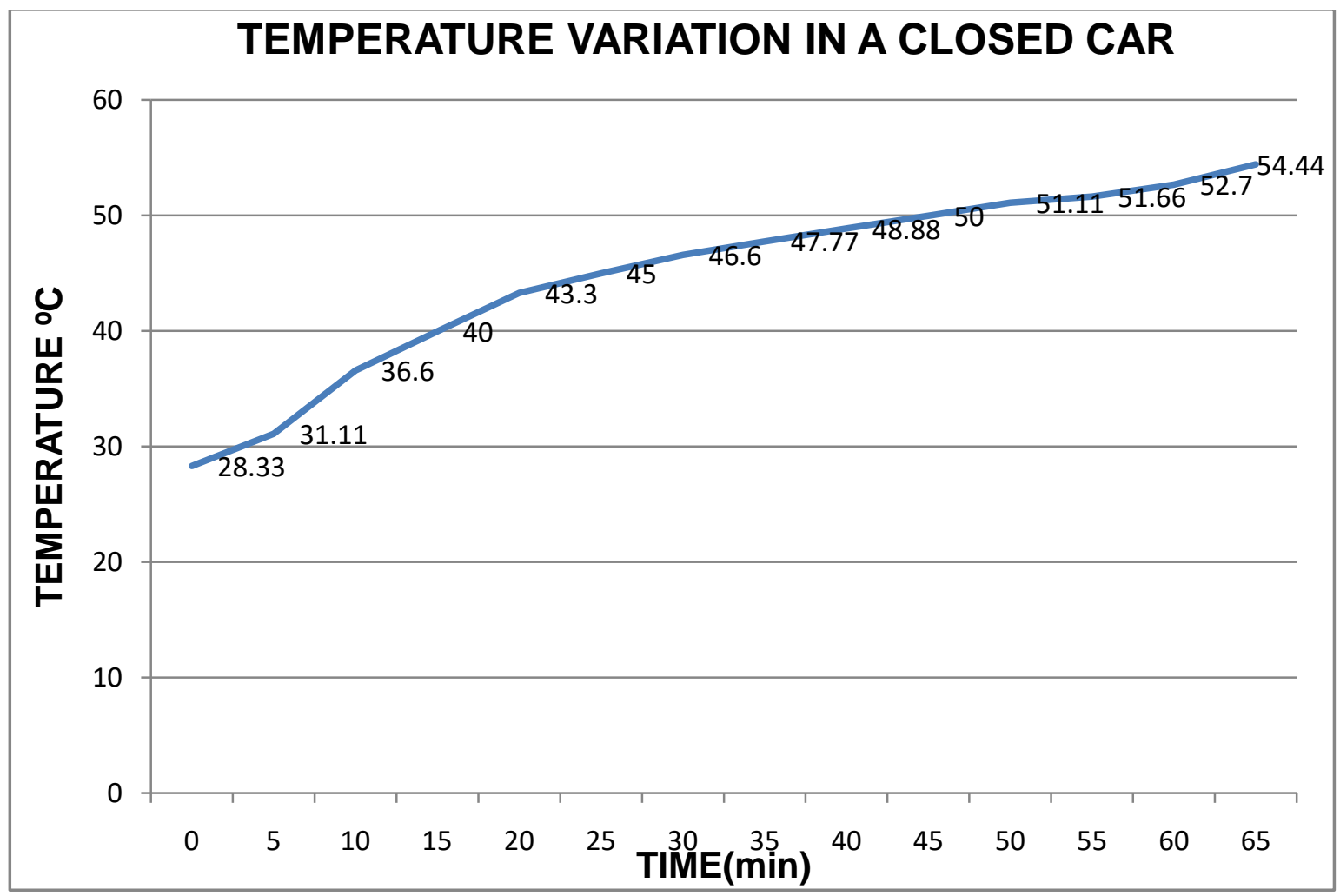

Fig 4.1 Temperature variation in a closed car

Figure 4.1; depicts that, when the car is closed, in the initial period, the temperature increases rapidly from the ambient temperature. With further passage of time, the temperature increases but at a slower rate. In 60 minutes, the temperature increased from 28 degree to 54 degree. This variation is thus harmful and fatal to the essential life. 


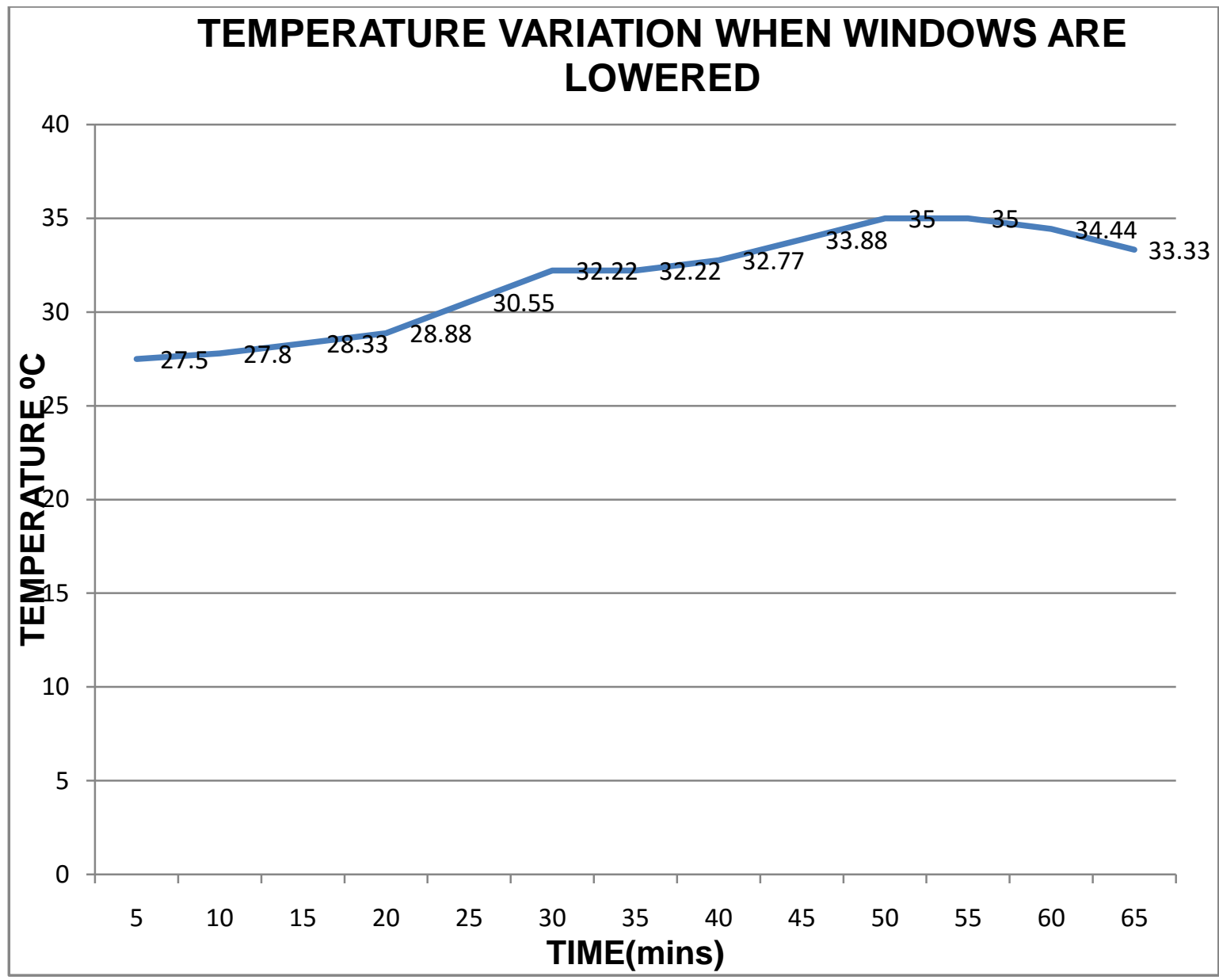

Fig 4.2 Temperature variation when windows are lowered

Figure 4.1; depicts that, with the windows lowered, the temperature increases at very low rate. In a period of 60 minutes, the temperature increased from 27.5 degree to 33.33 degree. This variation lies within the safe limit.

\section{Conclusions}

A mechatronic system consisting of sensors and actuators has been successfully developed and has been implemented in a prototype car. It efficiently and successfully lowered the window and thus allowed air to circulate which resulted in lowering the temperature. This being a cost effective model can be improved with future modification.

Based on the above research work, the following conclusions were drawn

- With the help of sensors and actuators window glass is lowered and circulation of fresh air takes place.

- Temperature inside the car is lowered and system prevents suffocation by intelligent sensing which works efficiently.

- The system developed is economical without any compromise on its functioning. 


\section{REFERENCES}

1) Adafruit. 2016, PIR datasheet. Available from: $<$ http://learn.adafruit.com/downloads/pdf/pir-passive-infrared-proximity-motionsensor.pdf $>$

2) Atmel. 2016, ATMEGA328P. Available from: $\langle$ http://www.atmel.com/devices/ATMEGA328P.aspx >

3) Canine College, 2012. Temperature variation in car. Available from: $<$ http://caninecollegemi.com/1758/pets-in-vehicles/temperature-inside-car-chart-2/>

4) Dulin M.J., Seip R.,( 2002). WO2002087910A2. USA: Google Patents.

5) Electrical4U. 2015, Servomotor working. Available from:< http://www.electrical4u.com/servo-motor-servo-mechanism-theory-and-workingprinciple>

6) Kids and car. 2016, Children death due heatstroke in car. Available from: <http://www.kidsandcars.org/heatstroke.html >

7) Liu C. (2001). US6263272. USA: Google Patents.

8) Liu j, (2000). US6138068. USA: Google Patents

9) Muhamad and Rasidi, 2013. In-Car Suffocating Prevention Using Image Motion Detection. Recent Advances in Circuits, System and Automatic Control, 145-150.

10) National highway traffic safety administration. 2015, heatstroke death in car. Available from: < https:// www.nhtsa.gov/heatstroke>.

11) Rajput, R.K, 2005. Heat and mass transfer, S.Chand.

12) San Francisco State University, Department of Geoscience. 2015, Cause of heatstroke deaths in car. Available from: 〈http://www.ggweather.com/heat/index.htm>

13) Garethiya et al., 2015. Affordable System for Alerting, Monitoring and Controlling Heat Stroke inside Vehicles. International Conference on Industrial Instrumentation and Control (IClC), College of Engineering Pune, India, 1506-1511.

14) Texas instruments. 2016, LM 35 specification. Available from: $\langle$ http://www.ti.com/lit/ds/symlink/lm35.pdf $>$

15) The Hindu.2015, suffocation death in car in India. Available from: $<$ http://www.thehindu.com/news/cities/Delhi/two-kids-die-of-suffocation-in-alocked-car/article7636503.ece $>$.

16) Quadri and Jose, 2013. Computational Analysis of Thermal Distribution Within Passenger Car Cabin. International Journal on Theoretical and Applied Research in Mechanical Engineering IJTARME) 2, 2319-3182. 